\title{
ISCHEMIC-INDUCED ALTERATIONS IN CARDIAC SENSITIVITY TO DIGITALIS
}

\author{
DAVID D. KU * and BENEDICT R. LUCCHESI ** \\ Department of Pharmacology and The Upjohn Center for Clinical Pharmacology, The University of Michigan \\ Medical School, Ann Arbor, Michigan 48109, U.S.A.
}

Received 13 March 1979, accepted 24 April 1979

D.D. KU and B.R. LUCCHESI, Ischemia-induced alterations in cardiac sensitivity to digitalis, European J. Pharmacol. 57 (1979) 135-147.

Intravenous infusion of acetylstrophanthidin to 6 dogs, after a $60 \mathrm{~min}$ left anterior descending coronary artery occlusion, was associated with a $43.0 \pm 10.5 \%$ decrease in the dose of digitalis needed to produce ventricular arrhythmias as compared to the pre-ischemic dose $(97.5 \pm 8.0 \mu \mathrm{g} / \mathrm{kg})$. Reperfusion of the ischemic region for $2 \mathrm{~h}$ after a $90 \mathrm{~min}$ occlusion resulted in a $54.4 \pm 6.7 \%$ decrease in the arrhythmogenic dose. Direct intracoronary infusions of digitalis into the ischemic region, after a $90 \mathrm{~min}$ coronary occlusion followed by $2 \mathrm{~h}$ of reperfusion, was associated with a $47.7 \pm 6.4 \%$ decrease in the dose of digitalis needed to produce arrhythmias. The preischemic (control) arrhythmogenic dose of digitalis via the intracoronary infusion method was $1.5 \pm 0.3 \mu \mathrm{g} / \mathrm{kg}$ (mean \pm S.E.M. of 7 dogs). Sodium pump activity, estimated from the ouabain-sensitive ${ }^{86} \mathrm{Rb}$ uptake in sodiumloaded ventricular slices, was significantly higher in slices obtained from the ischemic regions $(6.84 \pm 0.30 \mathrm{nmoles}$ ${ }^{86} \mathrm{Rb} / \mathrm{mg}$ dry wt. (mean \pm S.E.M.), than from the non-ischemic regions $(3.43 \pm 0.64 \mathrm{nmoles} 86 \mathrm{Rb} / \mathrm{mg} \mathrm{dry}$ wt.). Sensitivity of the sodium pump activity to the inhibitory effect of ouabain also was increased in the ischemic regions as indicated by a shift in the log dose-response curve to the left. Thus, it appears that there is an increase in myocardial sensitivity to the toxic effect of digitalis after temporary ischemia and it appears to be related to an increase in the sensitivity of the $\mathrm{Na}^{+}, \mathrm{K}^{+}$-ATPase or sodium pump to the inhibitory effect of digitalis.

Membrane $\mathrm{Na}^{+}, \mathrm{K}^{+}$-ATPase Ouabain
Intracoronary infusion ${ }^{86} \mathrm{Rb}$ uptake
Acetylstrophanthidin Cardiac arrhythmias

myocardial infarction has been controversial. The controversy results mainly from evidence accumulated from both experimental and clinical observations suggesting an increased tendency of digitalis to induce ventricular arrhythmias after acute myocardial infarction (Bellet et al., 1934; Travell et al., 1938; Hood et al., 1967; Morris et al., 1969; Kumar et al., 1970; Morrison and Killip, 1971). The mechanism(s) of these reported increases in myocardial sensitivity to the toxic effects of digitalis after acute myocardial infarction have not been studied extensively. Many recent studies had attempted to relate digitalis distribution and uptake in the ischemic myocardium to these toxic effects. Several investigators had reported that ischemic myocardial

\footnotetext{
* Present address: Department of Pharmacology, University of Alabama, University Station, Birmingham, Alabama 35294, U.S.A.

** Send all correspondence to: Benedict R. Lucchesi, Ph.D., M.D., Director, Upjohn Center for Clinical Pharmacology, Department of Pharmacology, M6322 Medical Science Building I, The University of Michigan Medical School, Ann Arbor, Michigan 48109, U.S.A.
}

\section{5}

(n)

\section{Introduction}

Congestive heart failure remains one of the major causes of in-hospital deaths in patients with acute myocardial infarction. Although digitalis is commonly indicated as the drug of choice for improving mechanical failure of the heart muscle, the use of digitalis in acute 
tissue accumulated significantly less labeled digitalis than normal, non-ischemic tissues (Beller et al., 1972, 1975, 1976; Hopkins and Taylor, 1973; Kuhlmann et al., 1975). Beller et al. (1976) had suggested that the decreased digitalis uptake by the ischemic tissue may be related to a defect or reduction in cardiac $\mathrm{Na}^{+}, \mathrm{K}^{+}$-ATPase, a putative receptor for the pharmacologic and/or toxic effects of digitalis. However, Kohama et al. (1971) had reported that a prolonged period of ischemia in skeletal muscle resulted in an increase in $\mathrm{Na}^{+}, \mathrm{K}^{+}$ATPase activity. Furthermore, other investigators had reported that acute myocardial infarction was not accompanied by an increase in myocardial sensitivity to digitalis (Sanazaro, 1957; Selzer, 1968; Constant, 1970; Reicansky et al., 1976).

Thus, the present study was undertaken to re-examine the changes in myocardial sensitivity to digitalis by performing digitalis sensitivity tests before and after temporary coronary artery occlusion. The digitalis sensitivity tests were performed by both intravenous and intracoronary drug infusion methods. The direct intracoronary digitalis administration had been shown to be effective in differentiating the intrinsic cardiac effects of digitalis from its extracardiac effects (Roberge et al,, 1968), and thus allows a more accurate determination of the mechanism of myocardial ischemia-induced changes in cardiac sensitivity to digitalis. In addition, the activity of the sodium pump and its sensitivity to the in vitro inhibitory effect of digitalis after temporary coronary occlusion were studied.

\section{Materials and methods}

\subsection{Experimental myocardial infarction}

Male, mongrel dogs weighing between 13.8 and $23.4 \mathrm{~kg}$ (mean of $17.1 \mathrm{~kg}$ ) were anesthetized with pentobarbital sodium $(30 \mathrm{mg} / \mathrm{kg}$, i.v.). Each dog was intubated with a cuffed endotracheal tube and ventilated with room

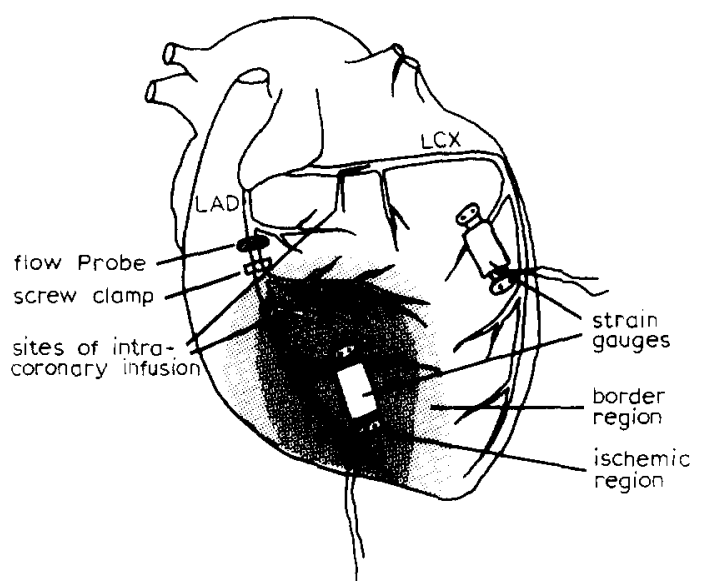

Fig. 1. A schematic representation of the canine myocardium. The left anterior descending coronary artery (LAD) was isolated and occluded below its first diagonal branch with a screw clamp. An electromagnetic flow probe was used to monitor LAD blood flow. Isometric contractile force was monitored by Walton-Brodie strain gauge arches. For the series of intracoronary drug infusion studies, a $25 \mathrm{G}$ needle was implanted in the coronary artery and connected to a Harvard infusion pump. LCX $=$ left circumflex coronary artery.

air using a Harvard respirator. Catheters were implanted in the left carotid artery for recording blood pressure using a Statham p23Db pressure transducer and in the left jugular vein for all subsequent drug administration. Heart rates were monitored from the Lead II electrocardiogram which triggered a cardiotachograph and all recordings were obtained on a Grass model 7 polygraph.

A lateral thoracotomy was performed through the fifth left intercostal space and the heart was suspended in a pericardial cradle. The left anterior descending coronary artery (LAD) was isolated below its first diagonal branch (fig. 1) and, at appropriate times, the blood flow was interrupted with a screw clamp. A calibrated electromagnetic flow probe (Carolina Medical Electronics) was placed around the anterior descending coronary artery for continuous monitoring of blood flow. At the end of the $90 \mathrm{~min}$ coronary occlusion period, blood flow was reinstituted over $35 \mathrm{~min}$ in an incremental 
fashion. At 0 time (i.e., after $90 \mathrm{~min}$ of occlusion) $10 \%$ of the pre-ischemic flow was re-instituted. Every $5 \mathrm{~min}$ an additional $10 \%$ of the pre-ischemic flow was re-instituted until $35 \mathrm{~min}$ had elapsed, at which time the screw clamp was removed. The gradual reinstitution of coronary flow minimized the development of a reactive hyperemic response and reduced the incidence of hemorrhagic infarction and ventricular fibrillation (Lucchesi et al., 1976; Ku and Lucchesi, 1978). Preliminary experiments with this slow, incremental release of the occluded left anterior descending coronary artery were demonstrated to be relatively free of any premature ventricular beats during the $2 \mathrm{~h}$ of reperfusion.

Regional myocardial contractile force was monitored using two calibrated WaltonBrodie strain gauge arches. One strain gauge was sutured to the free wall of the left ventricle in a region perfused by the left anterior descending coronary artery. The second strain gauge was positioned in the region perfused by the left circumflex coronary artery. The isometric contractile force signals were differentiated electronically to obtain $\mathrm{dF} / \mathrm{dt}$. In one series of experiments, epicardial electrograms were recorded by platinum electrodes embedded in a $3 \times 4 \mathrm{~cm}$ acrylic plaque (Perm, The Hygienic Dental Co., Akron, Ohio). The plaque was positioned and sutured to the free wall of the left ventricle so that recordings were obtained from both non-ischemic and ischemic regions. Epicardial electrograms were monitored sequentially and recorded on Grass polygraph before and $15 \mathrm{~min}$ after complete LAD occlusion. These recordings were repeated after $90 \mathrm{~min}$ of LAD occlusion and $2 \mathrm{~h}$ after reperfusion. Epicardial ST-segment elevations, 15 min after occlusion $\left(\mathrm{ST}_{15 \mathrm{~m}}\right)$, greater than 2 $\mathrm{mV}$ were considered abnormal as previously described (Maroko et al., 1971) and were arbitrarily graded as follows: normal (nonischemic), $\mathrm{ST}_{15 \mathrm{~m}}<2 \mathrm{mV}$; moderately ischemic (border), $2 \mathrm{mV}<\mathrm{ST}_{15 \mathrm{~m}}<6 \mathrm{mV}$; and ischemic, $\mathrm{ST}_{15 \mathrm{~m}}>6 \mathrm{mV}$. At the end of $2 \mathrm{~h}$ of reperfusion, the animals were sacrificed with an overdose of pentobarbital sodium. Transmural sections $(2 \mathrm{~cm} \times 1 \mathrm{~cm})$ of the left ventricle under the electrodes were excised for subsequent biochemical studies.

\subsection{Sodium pump studies}

Sodium pump activity was estimated by determining the ouabain-sensitive ${ }^{86} \mathrm{Rb}$ uptake as described previously (Ku et al., 1974, $1977 \mathrm{a}, \mathrm{b})$ with minor modifications. Briefly, canine ventricular slices (approximately 0.5 $\mathrm{mm}$ thick) were prepared using a StadieRiggs tissue slicer (A.H. Thomas Company, Philadelphia, Pennsylvania). Under normal condtitions, intracellular sodium concentration is the rate limiting determinant of monovalent cation pump activity (the rate of ouabain-sensitive ${ }^{86} \mathrm{Rb}$ uptake) (see Post, 1968; Thomas, 1972; Langer, 1974). Therefore, ventricular slices were preincubated at $0-2^{\circ} \mathrm{C}$ for $5 \mathrm{~min}$ in a $\mathrm{K}^{+}$-free and $\mathrm{Ca}^{2+}$-free $\mathrm{Krebs}-$ Henseleit solution for sodium "loading". Under these conditions, in which the intracellular sodium concentration is not the ratelimiting factor for monovalent cation pump activity, the rate of the ouabain-sensitive ${ }^{86} \mathrm{Rb}$ uptake would be determined by factors other than the intracellular sodium concentration. ${ }^{86} \mathrm{Rb}$ uptake was estimated by incubating slices with $2 \mathrm{mM} \mathrm{RbCl}$ containing tracer amounts of ${ }^{86} \mathrm{Rb}$ (New England Nuclear, Boston, Massachusetts; specific activity 3.5 $\mathrm{mCi} / \mathrm{mg}$ ) in a $\mathrm{K}^{+}$-free $\mathrm{Krebs}-$ Henseleit solution at $37^{\circ} \mathrm{C}$ in the presence or absence of $0.1 \mathrm{mM}$ ouabain. After a $10 \mathrm{~min}$ incubation period, slices were rinsed three times by immersing in separate $\mathrm{K}^{+}$-free solutions containing non-radioactive $\mathrm{RbCl}(2 \mathrm{mM})$ and blotting each time with filter paper. Radioactivity was estimated using a $\gamma$ scintillation spectrometer. The difference in ${ }^{86} \mathrm{Rb}$ uptake observed in the presence and absence of ouabain was calculated as the ouabain-sensitive ${ }^{86} \mathrm{Rb}$ uptake which represented approximately $40 \%$ of the total ${ }^{86} \mathrm{Rb}$ uptake. For the series of dose-response studies with ouabain, 
ventricular slices from the non-ischemic and ischemic regions were incubated in various concentrations of ouabain and the maximum inhibition of ${ }^{86} \mathrm{Rb}$ uptake by the highest dose of ouabain tested, $0.1 \mathrm{mM}$, served as $100 \%$ inhibition.

\subsection{Acetylstrophanthidin titration test}

The acetylstrophanthidin titration test was performed as described previously (Lucchesi and Shivak, 1964). In the first series of experiments, acetylstrophanthidin was adminstered intravenously at a rate of $75 \mu \mathrm{g} / \mathrm{min}$ using a Harvard infusion pump, whereas, in a second series of experiments, acetylstrophanthidin was administered directly into either the left anterior descending or left circumflex coronary artery via a $25 \mathrm{G}$ needle, at a rate of $2 \mu \mathrm{g} / \mathrm{min}$. The end-point of the titration test was the first electrocardiographic evidence of a loss of sinus node dominance as indicated by ventricular tachycardia (three or more consecutive ventricular beats) or idioventricular rhythm lasting for at least one minute (Lucchesi and Shivak, 1964). The digitalis titration test was performed before, during and after experimental myocardial infarction. Thus, each animal served as its own control and the toxic doses in the successive digitalis titration tests were compared to their control, pre-infarction dose.

\subsection{Miscellaneous}

All data were analyzed statistically using Student's paired $t$-test. $\mathrm{P}$ values smaller than 0.05 were considered to be statistically significant. The half-maximal inhibition of ${ }^{86} \mathrm{Rb}$ uptake by ouabain was estimated by the method of probit analysis.

\section{Results}

\subsection{Effect of myocardial ischemia on the cardiac sensitivity to digitalis}

Fig. 2 shows a typical tracing of the cardiac hemodynamic responses during an intravenous acetylstrophanthidin titration test. Intravenous infusion of acetylstrophanthidin, $75 \mu \mathrm{g} / \mathrm{min}$, resulted in an increase in mean arterial blood pressure from $140 \pm 6$ to $155 \pm 6 \mathrm{~mm} \mathrm{Hg}$ (mean \pm S.E.M. of $6 \mathrm{dogs}$ ) and a decrease in heart rate from $171 \pm 8$ to $116 \pm 12$ beats/ min with a prolongation of the $\mathrm{P}-\mathrm{R}$ interval. There was a $54.4 \pm 19.8 \% \quad(65.6 \pm 7.5 \mathrm{~g})$ increase in isometric contractile force in the region of the left ventricular myocardium perfused by the left circumflex coronary artery and a $53.7 \pm 13.3 \%(80.3 \pm 12.8 \mathrm{~g})$ increased in isometric force in the region perfused by the left anterior descending coronary artery. Continued infusion of acetylstrophanthidin resulted in a ventricular dysrhythmia. The averaged arrhythmogenic dose of acetyl. strophanthidin was $97.5 \pm 8.0 \mu \mathrm{g} / \mathrm{kg}$. Normal sinus rhythm recovered in $4.0 \pm 0.8$ min upon termination of the intravenous drug infusion.

Fig. 3 summarizes the results obtained from the intravenous acetylstrophantidin titration test in 6 control (sham-operated) animals and in 6 animals with experimentally induced myocardial ischemia. In the control animals, without myocardial ischemia, repeated intravenous acetylstrophanthidin titration tests every $2 \mathrm{~h}$ resulted in a $10.1 \pm 5.2 \%$ and $18.0 \pm 4.8 \%$ decrease in the arrhythmogenic dose during the second and third tests, respectively. The decrease in the arrhythmogenic dose of acetylstrophanthidin in the repeated tests was probably due to residual circulating digitalis in the animal. In the 6 animals with experimental myocardial ischemia, however, there was an average $43.0 \pm 10.5 \%$ decrease in the arrhythmogenic dose $60 \mathrm{~min}$ after left anterior descending coronary occlusion, as compared to the pre-ischemic dose. This was further reduced $(-54.4 \pm 6.7 \%)$ when the hearts were re-perfused for $2 \mathrm{~h}$ after a $90 \mathrm{~min}$ occlusion with a concomittant increase in the duration of arrhythmias $(14.5 \pm 4.1 \mathrm{~min})$.

In order to identify the origin of the increased cardiac sensitivity to digitalis, the acetylstrophanthidin titration test was performed by a direct intracoronary drug infusion method as described previously (Roberge 

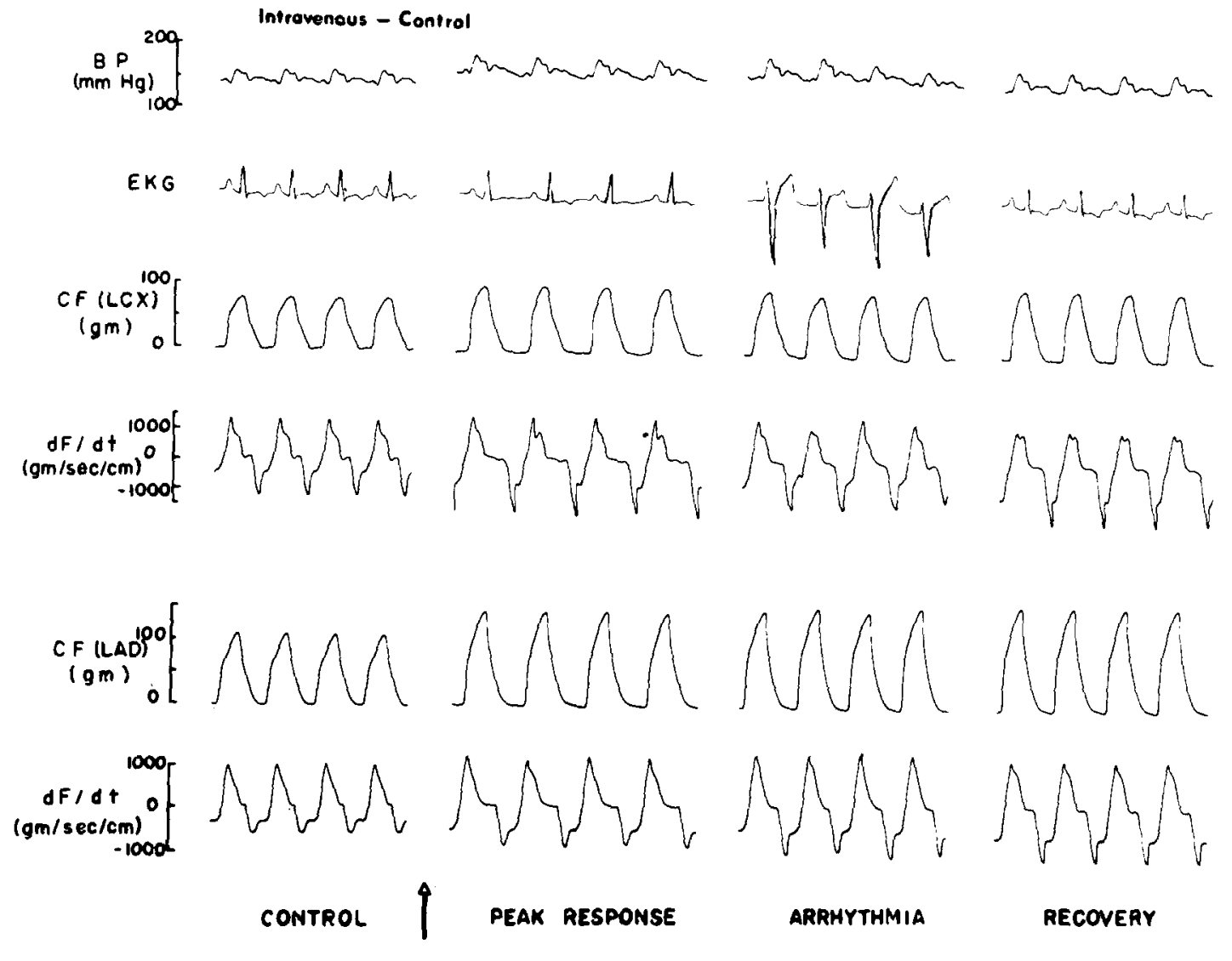

ARRHYTHMIA

RECOVEAY

ORUG

Fig. 2. The effect of intravenous infusion of acetylstrophanthidin into the dog. Acetylstrophanthidin was infused into the jugular vein at a rate of $75 \mu \mathrm{g} / \mathrm{min}$. The end point of the digitalis titration test was defined as the first electrocardiographic evidence of a loss of sinus node dominance for at least $1 \mathrm{~min}$. CF (LCX) indicates isometric contractile force of the left ventricle perfused by left circumflex coronary artery, whereas CF (LAD) indicates isometric contractile force of the left ventricle perfused by left anterior descending coronary artery. The averaged time to reach ventricular arrhythmia in 6 dogs was $23.3 \pm 2.9$ min and averaged recovery time was $4.0 \pm 0.8$ min.

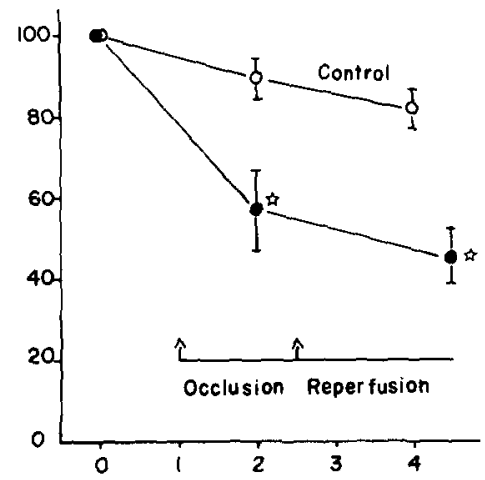

Fig. 3. Percent changes in the arrhythmogenic dose of acetylstrophanthidin in the control and experimental myocardial infarction animals during intravenous digitalis titration tests. Successive acetylstrophanthidin titration tests every $2 \mathrm{~h}$ in control animals, without myocardial infarction (open circles), resulted in a $10.1 \pm 5.2 \%$ and $18.0 \pm 4.8 \%$ decrease in the arrhythmogenic dose of digitalis in the second and third trials, respectively. In the experimental myocardial infarction group (closed circles), there was a mean $43.0 \pm 10.5 \%$ decrease in the arrhythmogenic dose $60 \mathrm{~min}$ after left anterior descending coronary occlusion. This was further reduced $(-54.4 \pm 6.7 \%)$ when the occluded region was allowed to reperfuse for $2 \mathrm{~h}$ after a $90 \mathrm{~min}$ occlusion. Vertical lines represent the standard error of the mean of 6 animals. Asterisk indicates $P<0.05$. Ordinate: \% change of arrhythmogenic dose of acetylstrophanthidin (i.v.). Abscissa: time (h). 

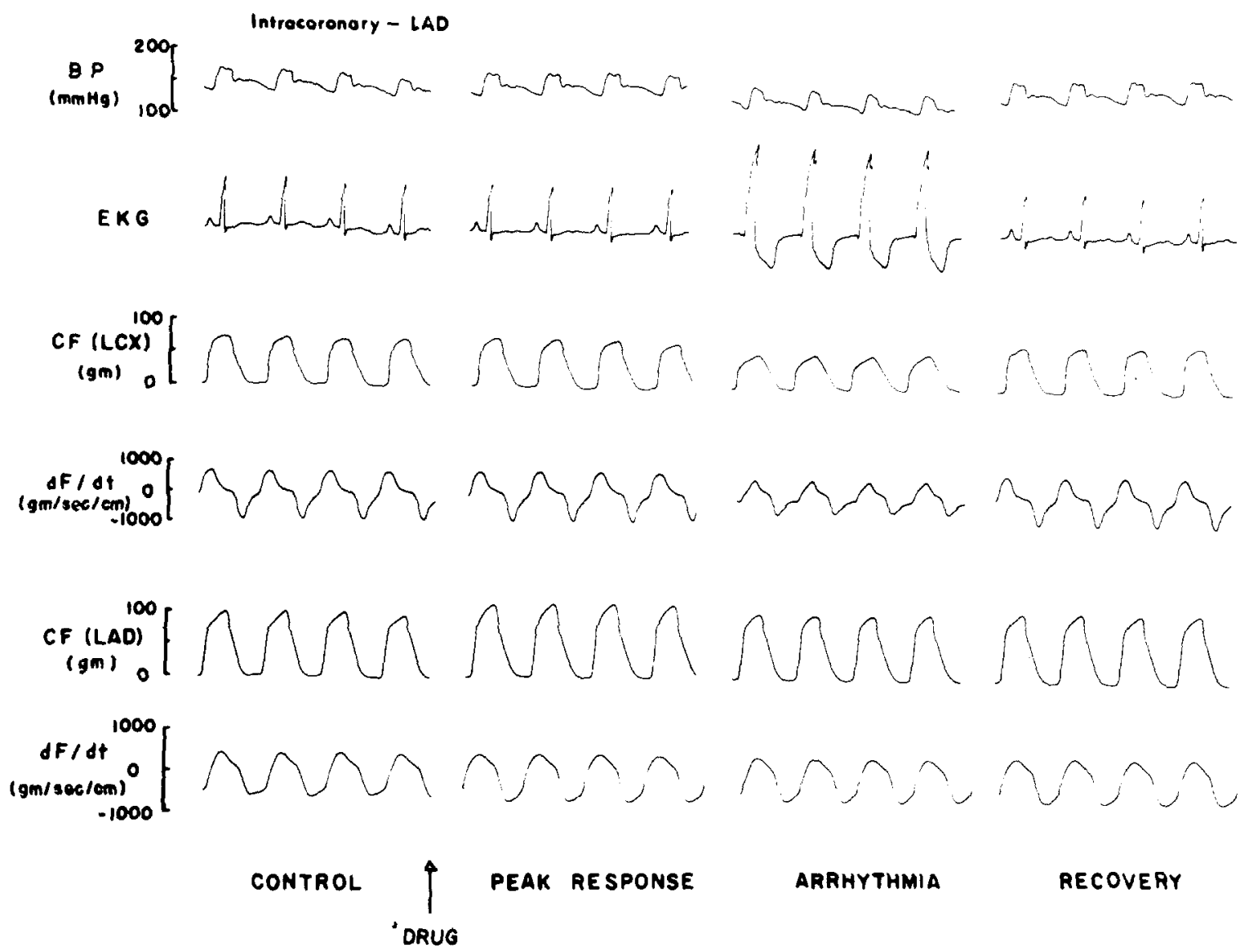

Fig. 4. The effect of direct intracoronary infusion of acetylstrophanthidin in the dog. Acetylstrophanthidin was infused into the left anterior descending coronary artery (LAD) at a rate of $2 \mu \mathrm{g} / \mathrm{min}$. At the peak response, digitalis produced an increase $(31.2 \pm 8.6 \%)$ in isometric contractile force (CF (LAD)) only in the region perfused by the left anterior descending coronary artery. No significant change in contractile force of the ventricle perfused by the left circumflex coronary artery (CF (LCX)). Arterial blood pressure and heart rate were also not affected. Continued infusion of digitalis into the LAD resulted in ventricular dysrhythmias. The average time to reach arrhythmia in seven dogs was $13.6 \pm 2.1 \mathrm{~min}$. The time for recovery of normal sinus rhythm after the termination of the drug was $5.8 \pm 1.1 \mathrm{~min}$.

et al., 1968; Hood et al., 1968) to differentiate the intrinsic cardiac effects of digitalis from its extra-cardiac effects. The results of a typical intracoronary acetylstrophanthidin titration test is shown in fig. 4. Direct intracoronary infusion of digitalis into the left anterior descending coronary artery resulted in an average $31.2 \pm 8.6 \%$ (mean \pm S.E.M. of 7 animals) increase in isometric contractile force in the region of the left vehicle perfused by the left anterior descending coronary artery. There was no significant change in force in the left circumflex coronary artery perfused region. The arterial blood pressure and heart rate were not altered by this direct intracoronary administration of acetylstrophanthidin. Continued infusion of acetylstrophanthidin resulted in ventricular dysrhythmia. The arrhythmogenic dose of acetylstrophanthidin via the intracoronary route was $1.5 \pm 0.3 \mu \mathrm{g} / \mathrm{kg}$. Similar results were obtained with infusion of acetylstrophanthidin 


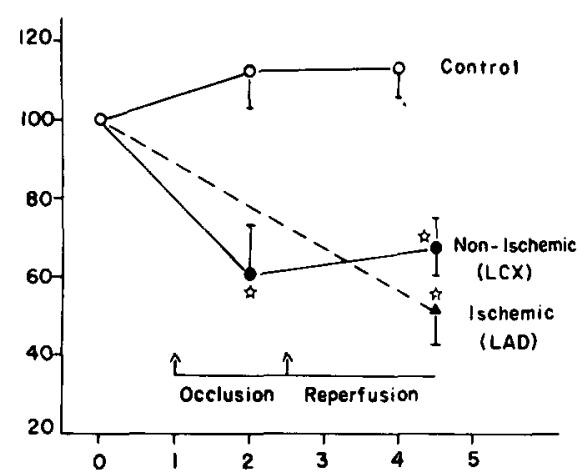

Fig. 5. Percent changes in the intracoronary arrhythmogenic dose of acetylstrophanthidin in the control and experimental myocardial infarction animals. Due to the small amount of drug required by this infusion method, repeated AS titration tests did not result in an accumulation of drug and the successive arrhythmogenic doses were not significantly altered in the control animals (open circles). Repeated acetylstrophanthidin titration tests in the left circumflex coronary artery perfused region (non-ischemic and possibly border regions; closed circles) during and after the left anterior descending coronary artery occlusion resulted in a $33.9 \pm 11.1$ and $31.7 \pm 7.4 \%$ decrease in the arrhythmogenic dose as compared to the pre-ischemic doses, respectively. In the ischemic region (closed triangle), after a $90 \mathrm{~min}$ left anterior descending coronary artery occlusion and $2 \mathrm{~h}$ of reperfusion, repeated digitalis titration tests resulted in a $47.7 \pm 6.4 \%$ decrease in the arrhythmogenic dose. Vertical lines indicate the standard error of the mean of 6 dogs; asterisk indicates $\mathrm{P}<0.05$. Ordinate: \% change of arrhythmogenic dose of acetylstrophanthidin (i.c.). Abscissa: time (h).

into the left circumflex coronary artery during which the positive inotropic response was observed only in the ventricular muscle being perfused by the left circumflex and not in the left anterior descending coronary artery.

Fig. 5 summarizes the results obtained from the direct intracoronary digitalis titration tests. In the 7 control, sham-operated animals, repeated digitalis titration tests did not cause drug accumulation and the arrhythmogenic doses were slightly increased in the successive digitalis titration tests. In the 6 animals with experimental myocardial ischemia, repeated infusion of acetylstrophan- thidin into the left circumflex coronary artery, i.e., area of non-ischemic and possibly border regions, after a $90 \mathrm{~min}$ occlusion of the left anterior descending coronary artery, resulted in a $33.9 \pm 11.1 \%$ decrease in the arrhythmogenic dose of digitalis. A similar decrease $(13.7 \pm 7.4 \%)$ in the toxic dose of digitalis was obtained when the occluded left anterior descending coronary was reperfused for $2 \mathrm{~h}$ after a $90 \mathrm{~min}$ occlusion. Intracoronary digitalis titration tests in the left anterior descending coronary artery (i.e., the ischemic region) were not performed $60 \mathrm{~min}$ following its occlusion because the blood flow was stopped at this time period. Repeated acetylstrophanthidin titration tests in the left anterior descending coronary artery, after a 90 min occlusion and $2 \mathrm{~h}$ of reperfusion, however, resulted in a $47.7 \pm 6.4 \%$ decrease in the arrhythmogenic dose.

The time required for the recovery of normal sinus rhythm after termination of either intravenous $(4.0 \pm 0.8 \mathrm{~min}$, mean \pm S.E.M. of 6 animals) or intracoronary (5.8 \pm $1.1 \mathrm{~min}$, mean \pm S.E.M. of 7 animals) digitalis titration tests was not significantly different in the control animals without experimental myocardial ischemia. Repeated intracoronary digitalis titration tests in these animals did not alter the recovery times. In the 5 animals with experimental myocardial ischemia, repeated intracoronary digitalis titration tests in the non-occluded left circumflex coronary artery, during and after experimental myocardial ischemia, did not result in any change in the recovery times $(3.2 \pm 1.1 \mathrm{~min})$. However, in the ischemic region (left anterior descending coronary artery), following a 90 min coronary occlusion and $2 \mathrm{~h}$ of reperfusion, ventricular dysrhythmias persisted for $17.9 \pm 1.1 \mathrm{~min}$ after termination of the intracoronary drug infusion. Thus, it appears that the duration of action of digitalis in the region perfused by the left anterior descending coronary artery (ischemic region) was prolonged, which could be attributed to the observed decrease in the arrhythmogenic dose of digitalis after experimental myocardial ischemia. 


\subsection{Effect of myocardial ischemia on sodium pump activity}

In order to determine the sodium pump activity and its sensitivity to the inhibitory effect of digitalis in vitro, another series of 5 animals with experimental myocardial ischemia was prepared. These animals had not been subjected to any previous digitalis titration test.

Sodium pump activity, estimated from the ouabain-sensitive ${ }^{86} \mathrm{Rb}$ uptake, was determined in myocardial slices obtained from non-ischemic, moderately ischemic (border), and ischemic regions after a $90 \mathrm{~min}$ left anterior descending coronary artery occlusion and $2 \mathrm{~h}$ of reperfusion. These three regions were determined from the relative epicardial ST-segment elevation $15 \mathrm{~min}$ after coronary occlusion and the subsequent development of $\mathrm{Q}$-waves after $2 \mathrm{~h}$ of reperfusion (fig. 6). In the non-ischemic region, the ouabain-sensitive portion of ${ }^{86} \mathrm{Rb}$ uptake by the sodium-loaded ventricular slices was $3.43 \pm 0.64$ nmoles ${ }^{86} \mathrm{Rb} / \mathrm{mg}$ tissue (dry weight). This value was not different from the previously published results in normal canine ventricular slices $(\mathrm{Ku}$ et al., 1977b). In the border region, there was a small but significant increase in ouabainsensitive ${ }^{86} \mathrm{Rb}$ uptake $(5.26 \pm 0.70$ nmoles ${ }^{86} \mathrm{Rb} / \mathrm{mg}$ tissue (dry weight)). This was increased further in the ischemic region; achieving a value almost two-times (6.84 \pm $0.30 \mathrm{nmoles}{ }^{86} \mathrm{Rb} / \mathrm{mg}$ tissue (dry weight)) as high as that in the non-ischemic region. The non-specific or ouabain-insensitive portions of ${ }^{86} \mathrm{Rb}$ uptake was not reduced significantly in the border and ischemic regions ( -7.6 and $-8.3 \%$, respectively). Intracellular water content was increased from $73.9 \pm$ $0.9 \%$ in the non-ischemic region to $75.0 \pm 1.1$ and $77.7 \pm 0.7 \%$ in the border and ischemic regions.

Acetylstrophanthidin was selected as the digitalis derivative in the digitalis titration test because of its rapid onset and short duration of action. This allows one to perform an intravenous digitalis titration test

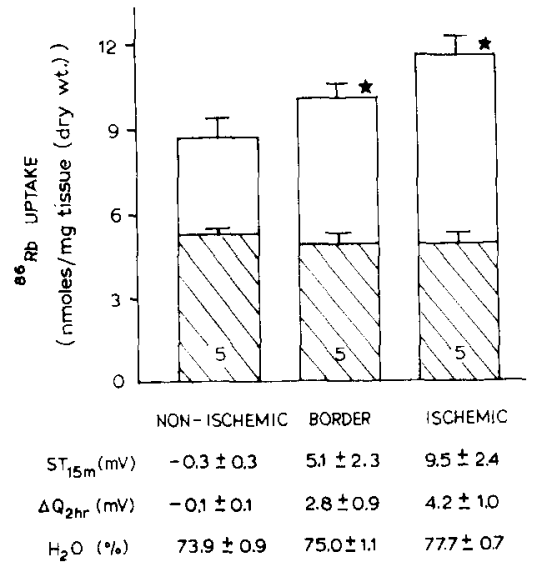

Fig. 6. Effects of temporary myocardial ischemia on ${ }^{86} \mathrm{Rb}$ uptake by canine ventricular slices. After a $90 \mathrm{~min}$ left anterior descending coronary occlusion and $2 \mathrm{~h}$ of reperfusion, ventricular slices (approximately $0.5 \mathrm{~mm}$ thick) obtained from non-ischemic, border and ischemic regions were pre-incubated for $5 \mathrm{~min}$ at $0-2^{\circ} \mathrm{C}$ in a $\mathrm{K}^{+}$-free and $\mathrm{Ca}^{2+}$-free $\mathrm{Krebs}-$ Henseleit solution for sodium "loading" prior to assay for ${ }^{86} \mathrm{Rb}$ uptake. The total height of the bars and slashed bars represents the ${ }^{86} \mathrm{Rb}$ uptake in the absence and presence of $0.1 \mathrm{mM}$ ouabain. Thus, open bars represent the ouabain-sensitive component of ${ }^{86} \mathrm{Rb}$ uptake. The number in the bars indicates the number of experiments. Vertical lines represent the S.E.M.; asterisk indicates $\mathrm{P}<0.05$. Epicardial STsegment elevation $15 \mathrm{~min}$ after coronary occlusion and $Q$-waves development after $90 \mathrm{~min}$ of occlusion and $2 \mathrm{~h}$ reperfusion were used to identify the normal, border and ischemic regions. The percent water content of the slices was determined from the difference between the wet weight and dry weight of

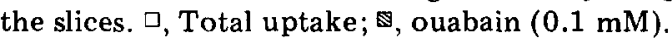

before, during, and after experimental myocardial infarction in a relatively short period $(4-5 \mathrm{~h})$. Measurement of sodium pump transport activity from the ouabain-sensitive portion of ${ }^{86} \mathrm{Rb}$ uptake is well documented (Ku et al., 1974, 1977a, 1977b) and has been shown to be highly sensitive to the inhibitory effects of digitalis (Ku et al., 1974, 1977b). Since ouabain and acetylstrophanthidin presumably bind to the same site on $\mathrm{Na}^{+} \mathrm{K}^{+}$-ATPase to exert their effects, the sodium pump activity measurement and its sensitivity to the inhibitory effect of digitalis was performed with a more stable digitalis, 


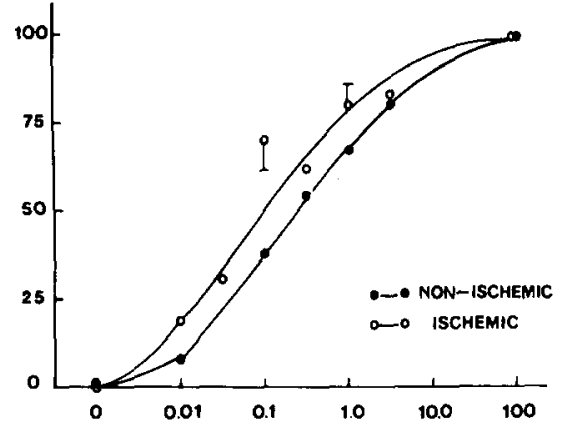

Fig. 7. Effect of ouabain on ${ }^{86} \mathrm{Rb}$ uptake by the sodium-loaded canine ventricular slices after temporary myocardial ischemia. After a $90 \mathrm{~min}$ left anterior descending coronary artery occlusion and $2 \mathrm{~h}$ of reperfusion, 7-8 slices (approximately $0.5 \mathrm{~mm}$ thick) of ventricular muscle from the non-ischemic (closed circles) and ischemic region (open circles) were pre-incubated for $5 \mathrm{~min}$ at $0-2^{\circ} \mathrm{C}$ in a $\mathrm{K}^{+}$-free and $\mathrm{Ca}^{2+}$-free Krebs-Henseleit solution for sodium "loading" prior to ${ }^{86} \mathrm{Rb}$ uptake assay. ${ }^{86} \mathrm{Rb}$ uptake was determined in the presence of various concentrations of ouabain. The maximum inhibition of ${ }^{86} \mathrm{Rb}$ uptake by $0.1 \mathrm{mM}$ ouabain served as $100 \%$ inhibition which was not significantly different between the two groups. Each point represents the average data obtained from 5 dogs. Ordinate: $\%$ inhibition of ${ }^{86} \mathrm{Rb}$ uptake. Abscissa: ouabain $(\mu \mathrm{M})$.

ouabain, instead of acetylstrophanthidin.

Fig. 7 shows the log dose-response curves of the sodium pump activity to the inhibitory effect of ouabain in canine ventricular slices obtained from non-ischemic ahd ischemic regions. The maximum inhibition of ${ }^{86} \mathrm{Rb}$ by the highest dose of ouabain tested, $0.1 \mathrm{mM}$, served as $100 \%$ inhibition. The ventricular slices obtained from the ischemic regions were more sensitive to the inhibitory effect of ouabain than the non-ischemic regions as indicated by the leftward shift in the ouabain concentration response curve. The halfmaximal inhibition of ${ }^{86} \mathrm{Rb}$ uptake by ouabain $\left(I_{50}\right)$ was reduced from $3.7 \pm 1.4 \times 10^{-7} \mathrm{M}$ (mean \pm S.E.M. of 5 experiments) in the nonischemic tissues to $1.3 \pm 0.3 \times 10^{-7} \mathrm{M}$ in the ischemic tissues.

\section{Discussion}

Acute myocardial infarction following experimental coronary artery occlusion in dogs and pigs had consistently been shown to result in an increase in myocardial sensitivity to the toxic effects of digitalis (a 20-30\% decrease in the toxic dose of digitalis as compared to the pre-ischemic dose) (Bellet et al., 1934; Travell et al., 1938; Hood et al., 1967; Morris et al., 1969; Kumar et al., 1970). The time course of development and duration of this altered myocardial sensitivity to digitalis, however, were not consistent. In the early study by Bellet et al. (1934), it was reported that there was no change in the toxic dose of digitalis $40 \mathrm{~min}$ after the ligation of the coronary artery. Significant decreases in the toxic dose of digitalis was observed, however, four days after coronary artery occlusion and was sustained for six weeks. In contrast, $\mathrm{Ku}$ mar et al. (1970) had reported that increased cardiac sensitivity to digitalis was observed only during the acute phase (one hour after coronary artery occlusion) and was not observed during the healing phase ( 2 and 7 days after coronary artery occlusion). The cause of these variable rates of onset and duration of altered cardiac sensitivity to digitalis is not clear. However, these variable rates and duration could, in part, explain the inability of several investigators to demonstrate an increase in myocardial sensitivity to digitalis, especially in the clinical settings (Sanazaro, 1957; Selzer, 1968; Constant, 1970; Reicansky et al., 1976). The present findings support, in part, the observations made by Kumar et al. (1970) that increased myocardial sensitivity (decreased arrhythmogenic dose) was observed $1 \mathrm{~h}$ after coronary occlusion and further demonstrated that this increased myocardial sensitivity to digitalis was sustained for at least $2 \mathrm{~h}$ after $90 \mathrm{~min}$ of coronary occlusion.

The origin or site of this altered myocardial sensitivity to digitalis after acute myocardial infarction is not well understood. Since all of the earlier experimental studies with digitalis 
sensitivity tests were performed after permanent ligation of a major coronary artery branch and reperfusion of the occluded region was not re-instituted (Bellet et al., 1934; Travell et al. 1938; Hood et al., 1967; Morris et al., 1969; Kumar et al., 1970). In addition, Bellet et al. (1934) had reported that the magnitude of the increase in myocardial sensitivity was related to the size of the infarcted myocardium. Thus, it had been suggested that the periphery of the ischemic myocardium (border region) might be the site of the altered myocardial sensitivity. The present study in dogs, using a model of temporary coronary occlusion followed by reperfusion, confirmed this hypothesis and further demonstrated that the ischemic myocardium may also contribute to the observed increase in myocardial sensitivity. The present findings demonstrated that a similar decrease (47.4 \pm $6.4 \%$ ) in the arrhythmogenic dose of digitalis was obtained when digitalis was administered directly (intracoronary) into the ischemic region after a 90 min coronary occlusion and $2 \mathrm{~h}$ of reperfusion (fig. 5). The direct intracoronary digitalis administration required approximately $1-2 \%$ of the dose required by the intravenous administration method to induce ventricular arrhythmia and, in addition, the cardiotoxicity occurred before any significant changes in heart rate and arterial blood pressure.

The mechansim(s) of the increase in myocardial sensitivity to the toxic effects of digitalis after acute myocardial infarction have not been studied extensively. Previous studies dealing with tissue distribution of labeled digitalis had indicated an uneven distribution of digitalis between the ischemic and non-ischemic myocardium (Beller et al., 1972, 1975, 1976; Hopkins and Taylor, 1973; Kuhlmann et al., 1975). The mechanism of the decreased digitalis uptake by the ischemic myocardium is not clear. It had been suggested that decreased digitalis uptake by the ischemic myocardial tissue may be related to a defect or reduction in cardiac $\mathrm{Na}^{+}, \mathrm{K}^{+}$-ATPase, a putative receptor for the pharmacologic and/ or toxic effects of digitalis. Willerson et al. (1977) had reported that cardiac $\mathrm{Na}^{+}, \mathrm{K}^{+}$. ATPase activity was depressed (approximately $20 \%$ ) as early as $40 \mathrm{~min}$ after coronary artery occlusion. Beller et al. (1976) had demonstrated that reduction in labeled digitalis uptake in the ischemic tissue after 2 and $6 \mathrm{~h}$ of coronary occlusion was correlated with a reduction in cardiac $\mathrm{Na}^{+}, \mathrm{K}^{+}$-ATPase activity. The present findings do not support the contention that temporary myocardial ischemia causes a decrease in $\mathrm{N}^{+}, \mathrm{K}^{+}$-ATPase or sodium pump activity. In the present study, after $90 \mathrm{~min}$ of coronary occlusion and $2 \mathrm{~h}$ of reperfusion, the ouabain-sensitive ${ }^{86} \mathrm{Rb}$ uptake by the ventricular slices, an estimate of sodium pump activity, was significantly higher in slices obtained from ischemic myocardium than from non-ischemic and moderately ischemic myocardium (fig. 6). The reason(s) for the apparent difference between the present findings and the earlier results are not certain. It appears that the method employed in the present study, i.e., the estimation of sodium pump activity by determining the ouabain-sensitive ${ }^{86} \mathrm{Rb}$ uptake in ventricular slices, has several advantages. The present method eliminates the necessity of lengthy treatment with deoxycholic acid and sodium iodide resulting in a more accurate estimate of the ischemia-induced changes in the myocardial cytoplasmic membrane occurring in vivo. It is also important to note that these same investigators (Beller et al., 1976), who demonstrated a reduction in $\mathrm{N}^{+}, \mathrm{K}^{+}$-ATPase activity, were unable to demonstrate a significant correlation between the reduction in digitalis uptake and cardiac $\mathrm{Na}^{+}, \mathrm{K}^{+}$-ATPase activity in the ischemic tissue after $1 \mathrm{~h}$ of coronary occlusion. Furthermore, it is well known that determination of total myocardial digitalis uptake after temporary coronary occlusion may be influenced by many other factors, such as changes in local blood flow and intracellular and extracellular cation concentrations. Thus, it appears from the present finding that a decrease in digitalis uptake by the ischemic myocardial tissue after tem. 
porary (90 $\mathrm{min}$ ) coronary occlusion may not be related to a decrease in the digitalis binding receptor.

The mechanism of the increase in sodium pump activity after $90 \mathrm{~min}$ of coronary artery occlusion and reperfusion is not clear. Since the increase in sodium pump activity was observed under the conditions in which the intracellular sodium concentration was not the rate-limiting factor for sodium pump activity, i.e., with sodium pre-loading prior to ${ }^{86} \mathrm{Rb}$ uptake studies, the results suggest that the myocardial ischemic process might have a direct stimulatory effect on sodium pump activity. It is well documented that myocardial ischemia is generally accompanied by an increase in intracellular sodium concentration (Lie et al., 1975; Polimeni and AlSadir, 1975; Bodenheimer et al., 1976), thus, it is possible that such an increase in intracellular sodium concentration during temporary myocardial ischemia could maximally activate the sodium pump activity when the occluded region was reperfused. Similar stimulation of sodium pump activity after increased sodium loading had also been reported (Ernst et al., 1967; Fletcher et al., 1967; Katz and Epstein, 1967; Ku et al., 1977a). It is important to note that sodium pump activity will eventually be depressed or damaged after prolonged myocardial ischemia and when the cardiac cells become necrotic. Thus, it is conceivable that the degree of sodium pump stimulation observed in the present study, after $90 \mathrm{~min}$ of coronary artery occlusion and $2 \mathrm{~h}$ reperfusion, may be underestimated because partial cell dysfunction may have occurred.

One of the remarkable features of the digitalis action is the diverse species-dependent differences in sensitivity to digitalis. It had been demonstrated that the divergent sensitivity of the myocardium to the pharmacologic effects of digitalis in various animal species is related to the divergent sensitivity of cardiac $\mathrm{Na}^{+}, \mathrm{K}^{+}$-ATPase to the in vitro inhibitory effect of digitalis (Repke et al., 1965). The present findings demonstrated that the sodium pump activity of the ischemic myocardial tissue was more sensitive to the inhibitory effect of digitalis than the nonischemic tissue. The half-maximal inhibition of ${ }^{86} \mathrm{Rb}$ uptake by ouabain was reduced from $3.7 \pm 1.4 \times 10^{-7} \mathrm{M}$ in the non-ischemic tissue to $1.3 \pm 0.3 \times 10^{-7} \mathrm{M}$ in the ischemic tissue (fig. 7). Although a statistically significant difference between the half-maximal inhibition $\left(I_{50}\right)$ of ${ }^{86} \mathrm{Rb}$ uptake by ouabain in the two regions was not obtained in the present study, it is important to note that the magnitude of increase in myocardial sensitivity (decrease in the intravenous arrhythmogenic dose of digitalis, $-54.4 \pm 7.6 \%$ ) after a $90 \mathrm{~min}$ coronary occlusion and reperfusion, is similar to that observed in the increased sensitivity of the sodium pump to ouabain in vitro (decrease in the half-maximal inhibition dose, $-64.9 \pm 8.1 \%$ ). Thus, it appears from the present findings that an increase in cardiac sensitivity to digitalis after $90 \mathrm{~min}$ of coronary occlusion may be related to an increase in sensitivity of sodium pump to the in vitro inhibitory effect of digitalis.

\section{Acknowledgements}

Supported in part by USPHS grant HL-19782-01 from the National Heart, Lung and Blood Institute. Dr. David D. Ku was supported by a Searle Fellowship in cardiovascular pharmacology and by a Michigan Heart Association Fellowship. A preliminary report of these findings was presented at the Fall Meeting of the American Society of Pharmacology and Experimental Therapeutics, August, 1977.

\section{References}

Beller, G.A., T.W. Smith and W.B. Hood, Jr., 1972, Altered distribution of tritiated digoxin in the infarcted canine left ventricle, Circulation 46, 572.

Beller, G.A., T.W. Smith and W.B. Hood, Jr., 1975, Effects of ischemia and coronary reperfusion on myocardial digoxin uptake, Amer. J. Cardiol. 36, 902.

Beller, G.A., J. Conroy and T.W. Smith, 1976, Ischemia-induced alterations in myocardial $\left(\mathrm{Na}^{+}, \mathrm{K}^{+}\right)$- 
ATPase and cardiac glucose binding, J, Clin. Invest. 57,341 .

Bellet, S., C.G. Johnson and A. Schecter, 1934, Effects of cardiac infarction on the tolerance of dogs to digitalis, Arch. Intern. Med. 54, 509.

Bodenheimer, M.M., V.S. Banka, R. Levites and R.H. Helfant, 1976, Temporal relation of epicardial electrographic, contractile and biochemical changes after acute coronary occlusion and reperfusion, Amer. J. Cardiol. 37, 486.

Constant, J., 1970, Digitalis in myocardial infarction changing concepts, N.Y. State J. Med. 70, 650.

Ernst, S.A., C.C. Goertemiller, Jr. and R.A. Ellis, 1967, The effect of salt regiment on the development of $\left(\mathrm{Na}^{+}, \mathrm{K}^{+}\right)$-dependent ATPase activity during the growth of salt glands of ducklings, Biochim. Biophys. Acta. 135, 682.

Fletcher, G.L., I.M. Stainer and W.N. Holmes, 1967, Sequential changes in the adenosinetriphosphatase activity and the electrolyte excretory capacity of the nasal glands of the duck (Anas platyrhynchos) during the period of adaptation to hypertonic saline, J. Exptl. Biol. 47, 375.

Hood, W.B., Jr., B. McCarthy and B. Lown, 1967, Myocardial infarction following coronary ligation in dogs. Hemodynamic effects of isoproterenol and acetylstrophanthidin, Circulation Res. 21, 191.

Hood, W.B., Jr., B. Letac, G. Roberg and B. Lown, 1968 , Direct digitalization of the myocardium. Hemodynamic effects, Amer. J. Cardiol. 22, 667.

Hopkins, B.E. and R.R. Taylor, 1973, Digoxin distribution in the dog's left ventricle in the presence of coronary artery ligation, J. Mol. Cell Cardiol. 5, 197.

Katz, A.I. and F.H. Epstein, 1967, The role of sodium-potassium-activated adenosine triphosphatase in the reabsorption of sodium by the kidney, J. Clin. Invest. 46, 1999.

Kohama, A., W.A. Boyn, C.M. Ballinger and I. Veda, 1971, Adenosine triphosphatase activities of subcellular fractions of normal and ischemic muscles, J. Surg. Res. 11, 297.

Ku, D., T. Akera, C.L. Pew and T.M. Brody, 1974, Cardiac glycosides. Correlations among $\mathrm{Na}^{+}, \mathrm{K}^{+}-$ ATPase, sodium pump and contractility in the guinea pig heart, Naunyn-Schmiedeb. Arch. Pharmacol. 285, 185.

Ku, D.D., T. Akera, M. Frank, T.M. Brody and J. Iwasa, 1977a, The effects of grayanotoxin I and $\alpha$-dihydrograyanotoxin II on guinea pig myocardium, J. Pharmacol. Exptl. Therap. 200, 363.

Ku, D.D., T. Akera, T.M. Brody and L.C. Weaver, $1977 \mathrm{~b}$, Chronic digoxin treatment on canine myocardial $\mathrm{Na}^{+}-\mathrm{K}^{+}$-ATPase, Naunyn-Schmiedeb. Arch. Pharmacol. 301, 39.

Ku, D.D. and B.R. Lucchesi, 1978, Effects of dime- thyl propranolol (UM-272, SC-27761) on myocardial ischemic injury in the canine heart after temporary coronary artery occlusion, Circulation 51,541 .

Kuhlmann, J., V. Kotte, E. VonLeitner, G. Arbeiter, R. Schroder, and N. Rietbrock, 1975, Concentration of digoxin, methyldigoxin, digitoxin and ouabain in the myocardium of the dog following coronary occlusion, Naunyn-Schmiedeb. Arch. Pharmacol. 287, 399.

Kumar, R., W.B. Hood, Jr., J. Joison, D.P. Gilmour, J.C. Norman and W.H. Abelmann, 1970, Experimental myocardial infarction. VI. Efficacy and toxicity of digitalis in acute and healing phase in intact conscious dogs, J. Clin. Invest. 49, 358.

Langer, G.A., 1974, Ionic movements and the control of contraction, in: The Mammalian Myocardium, eds. G.A. Langer and A.J. Brady (John Wiley and Son, Inc., New York, N.Y.) p. 193.

Lie, J.T., P.C. Pairolero, K.E. Holley, J.T. McCall, K.H. Tompson, Jr. and J.L. Titus, 1975, Time course and zonal variations of ischemia-induced myocardial cationic electrolyte derangements, Circulation 51, 860 .

Lucchesi, B.R. and R. Shivak, 1964, Effect of quinidine and procainamide upon acetylstrophanthidin cardiotoxicity, J. Pharmacol. Exptl. Therap. 143, 366.

Lucchesi, B.R., W.E. Burmeister, T.E. Lomas and G.D. Abrams, 1976, Ischemic changes in the canine heart as affected by the dimethyl quaternary analog of propranolol, UM-272 (SC-27761), J. Pharmacol. Exptl. Therap. 199, 310.

Maroko, P.R., J.K. Kjekshus, B.E. Sobel, T. Watanabe, J.W. Covell, J. Ross, Jr. and E. Braunwald, 1971, Factors influencing infaret size following experimental coronary artery occlusions, Circulation 43 , 67.

Morris, J.J., C.V. Taft, R.E. Whalen and H.D. McIntosh, 1969, Digitalis and experimental myocardial infarction, Amer. Heart J. 77, 342.

Morrison, J. and T. Killip, 1971, Serial serum digitalis levels in patients with acute myocardial infarction, Clin. Res. 19, 353 (Abstr.).

Polimeni, P.I. and J. Al-Sadir, 1975, Expansion of extracellular space in the non-ischemic zone of the infarcted heart and concomitant changes in tissue electrolyte contents in the rat, Circulation Res. 37 , 725.

Post, R.L., 1968, The salt pump of animal cell membrane, in: Regulatory Functions of Biological Membranes, ed. J. Jarnefeit (Elsevier Publishing Co., Amsterdam) p 163.

Reicansky, I., T.-B. Conradson, S. Homberg, L. Ryden, A. Waldenstrom and B. Wennerblom, 1976, The effect of intravenous digoxin on the occurrence of ventricular tachyarrhythmias in acute 
myocardial infarction in man, Amer. Heart J. 91, 705.

Repke, K., M. Est and J.H. Portius, 1975, Über die Ursache der Speciesunterschiede in der Digitalisempfindlichkeit, Biochem. Pharmacol. 14, 1785.

Roberge, G., W.B. Hood and B. Lown, 1968, Digitalization of the myocardium in the intact animal by direct coronary artery drug administration. I. Methodologic and pharmacologic considerations, Amer. J. Cardiol. 21, 213.

Sanazaro, P.J., 1957, Use of deslanoside in acute myocardial infarction and cardiac emergencies: A probative agent for assessing digitalis saturation and for intramuscular digitalization, Amer. Pract. 8,1933 .
Selzer, A., 1968, The use of digitalis in acute myo. cardial infarction, Progr. Cardiovasc. Dis. 10, 518.

Thomas, R.C., 1972, Electrogenic sodium pump in nerve and muscle cells, Physiol. Rev. 52, 563.

Travell, J., H. Gold and W. Modell, 1938, Effect of experimental cardiac infarction on response to digitalis, Arch. Intern. Med. 61, 184.

Willerson, J.T., F. Scales, A. Mukherjee, M. Platt, G.H. Templeton, G.S. Fink and L. Maximallian Buja, 1977, Abnormal myocardial fluid retention as an early manifestation of ischemic injury, Amer. J. Pathol. 87, 159. 